\title{
Ingrained Patriarchy, Opportunity Lost
}

\section{Barbara Chiarello, PhD}

Back in 1966, when I was a pre-med major at Brooklyn College, I was the victim of one of those freak accidents that occur in organic chemistry labs.

As I was inserting a glass rod into a rubber stopper, the rod broke and the needlelike tip of one part of the fragment pierced the lowest part of my left index finger, traveled under the skin and came out the front.

I stared in disbelief. What has just happened? The pain and the dripping blood propelled me to find my lab instructor. He had me sit down, then he took out the rod, wrapped a towel around my finger and called my father, who took me by subway to a nearby emergency room.

I was taking cough medicine and aspirin that day to lessen severe cold symptoms because I dared not miss a single class, especially since I was barely passing organic chemistry, a requirement for medical school. Perhaps I was in a drug-induced fog, or perhaps the glass rod had an imperfection. No matter, as neither explanation mitigated my fate.

Here I was, trying not to faint, sitting in a large exam room with two interns, one of whom would stitch up both gashes in my finger.

I studied the interns, one a male and one a female. As they worked on the patients who had arrived before me, I remember fervently wishing that the male doctor would tend my wound.

And so it was.

After, doctors couldn't sew up people without the use of both hands, especially their dominant hand.

Suddenly, I saw myself back in the hospital and realized that far from supporting the female intern that I hoped to be, I favored her male counterpart.

Not until decades later, when I learned how patriarchal discourses permeate the very air we breathe, did I retroactively understand why I never thought the female competent enough to perform a routine procedure.

In the two years I attended medical school, I experienced blatant sexism-Playboy centerfolds interspersed with more traditional anatomy slides; nurses who flirtatiously helped male medical students while ignoring members of their own sex who needed a patient's chart; being mistaken for a nurse despite wearing a name tag with M.D. after my name.

But those incidents were foisted on me. I was the passive recipient of longstanding assumptions about who did and who did not belong in medical school.

More disturbing was that I had been complicit in perpetuating misogynist stereotypes. After all, I could have requested the female intern. 